\title{
Drug use Among Undergraduates in Maiduguri, Northeast Nigeria
}

\author{
Roland Nnaemeka Okoro (ib) ${ }^{1, *}$ and Umar Lahai ${ }^{1}$ \\ ${ }^{1}$ Department of Clinical Pharmacy and Pharmacy Administration, Faculty of Pharmacy, University of Maiduguri, Maiduguri, Nigeria \\ "Corresponding author: Department of Clinical Pharmacy and Pharmacy Administration, Faculty of Pharmacy, University of Maiduguri, Maiduguri, Nigeria. Email: \\ orolandn@gmail.com
}

Received 2021 February 07; Revised 2021 April 22; Accepted 2021 April 26.

\begin{abstract}
Background: Drug use among students is a public health problem and the academic consequences cannot be overemphasized. Objectives: This study aimed to determine the prevalence and the pattern of drug use among undergraduates in Maiduguri and to identify the predictors.

Methods: This cross-sectional study was conducted among students of tertiary institutions in Maiduguri Metropolis, Nigeria. Data were collected using the WHO Student Drug Use questionnaire. The data collected with the survey instrument included sex, age, studentship, and job status in the past 12-months and various drugs used. Descriptive statistics such as frequency, mean and standard deviation were initially used to describe the study data. Chi-Square and Fisher's exact tests were used to test for significant difference, while multivariate logistic regression was used to identify determinants of drug use with a P-value $<0.05$ taken as significant Results: The overall prevalence of the past 12-months drug use was $14.3 \%$. Tobacco (9.6\%) followed by alcohol (8.1\%) was the most frequently used drug. Being a university student (odds ratio $=1.88[1.23-2.89]$ ) compared to polytechnic student, being a male $(1.55$ [1.04 - 2.31]) compared to female, aged 26 - 35 years (1.48 [0.95 - 2.31]) compared to 18 - 25 years were significantly more likely to use drugs. Additionally, being a part-time student in the past 12-months (2.16 [1.11 - 4.21]) compared to no studentship status in the past 12 months, and having a paid part-time jobs in the past 12-months (2.11 [1.36 - 3.27]) compared to none were significantly more likely to use drugs.

Conclusions: Our study revealed that a considerable proportion of students of higher education institutions in Nigeria use drugs. Drug use has grave implications for these students and may result in mental health disorders and poor academic performance. This highlights the importance of an effective drug prevention policy in higher education institutions.
\end{abstract}

Keywords: Drug Use, Maiduguri, Undergraduates, Nigeria

\section{Background}

Globally, 35 million people suffered from drug use disorders in 2018, while more than one-half of a million people died in 2017 as a result of drug use (1). Irrational drug use is a major public health problem all over the world (2). Non-medical use of psychoactive drugs, including alcohol and illicit drugs is termed substance abuse (3). One of the major health-related issues in Nigeria and other parts of the world is the inappropriate use of drugs by adolescents (4). It has been reported that alcohol and cannabis are the most frequently used by college students (5). In Nigeria, drug use is most common among those who are between the ages of 25 and 39 years in 2018 (6). This youthful age group is predominately found in the tertiary institutions of our country. Students in these tertiary institutions are at a stage of transition between dependence and independence. These students may use drugs due to various reasons, such as experimental curiosity, peer pres- sure, lack of parental supervision, personality problems due to socio-economic conditions, and the need for energy to work for long hours (7). Other factors are the availability of the drugs, the need to prevent the occurrence of withdrawal syndromes, advertisement of alcohol or cigarettes, unemployment and parental deprivation, and emotional and psychological stresses (anxiety, frustration, and economic depression) (7). However, among other dependents, the presence of drug users in the family is a major factor of drug use by adolescents. The World Health Organization reported that the risk of exposure to drug abuse has become one of the factors that influence the development of disease burden (8).

The review of the literature showed vast published studies on drug use among students of higher institutions of learning in Nigeria (9-11). However, these studies were performed in other geopolitical zones of the country. To our knowledge, no published study has attempted to investigate drug use among students of higher institutions 
in northeast, Nigeria.

\section{Objectives}

The objectives of this study were to determine the prevalence and the pattern of drug use among undergraduates in Maiduguri and to identify the socio-demographic predictors of their use.

\section{Methods}

A cross-sectional, descriptive survey was conducted between January-August 2019. This survey was purposively conducted in four higher institutions (College of Agriculture, College of Education, Polytechnic and University) in Maiduguri metropolis. Three of them are state-owned institutions, and the remainder is a federal University. These four were chosen because they are the largest tertiary institutions in Maiduguri.

Students of the study institutions made up the study population. Convenient sampling was used to select the participants while they were seated in the lecture halls waiting to receive lectures. Invited participants that agreed to participate in the study were informed about the purpose of the study and they gave written informed consent before completing the paper questionnaire. Two hundred and fifty (250) questionnaires were given out at the college of agriculture, 250 at the college of education, 370 at the polytechnic, and 580 at the university. The questionnaires were self-administered and anonymously completed by each student at his/her convenience. The completed questionnaires were returned to the focal person in each institution. Participation was on free will and no gifts were offered as incentives to the participants.

The study protocol was approved by the Faculty of Pharmacy Research Review Board, University of Maiduguri prior to data collection. The study data were collected using the 19-item drug use questionnaire adapted from a 22item WHO students drug-use questionnaire (12). The study instrument contains socio-demographic questions (items 1 - 6), last 12-month drug use (items 7 -18), any other drugs not mentioned before taken last year without a doctor or health worker telling you to do so (item 19). The data collected with the survey instrument included sex, age, studentship, and job status in the past 12-months and various drugs used.

Descriptive statistics such as frequency, mean and standard deviation were initially used to describe the study data. Chi-square and Fisher's exact tests were used to test for significant difference, while multivariate logistic regression analysis (no to drug use $=0$ versus yes to drug use
$=1$ ) was used to identify the determinants of drug use with a P-value $<0.05$ taken as significant. The statistical analysis was done with IBM statistical products and services solution (SPSS) version 20 for Windows software.

\section{Results}

One thousand two hundred valid filled questionnaires were returned from the four schools, giving an overall response rate of $81.8 \%$. Table 1 shows the socio-demographic variables of the study population. Most of the participants 734 (61.2\%) were males and between the ages 18 - 30 years (97.2\%). The mean age of the study population is $22.4 \pm 3.7$ years. Other socio-demographic characteristics of the participants are shown in Table 1.

\begin{tabular}{|c|c|}
\hline Variable & No. (\%) \\
\hline \multicolumn{2}{|l|}{ Sex } \\
\hline Female & $466(38.8)$ \\
\hline Male & $734(61.2)$ \\
\hline \multicolumn{2}{|l|}{ Age, $y$} \\
\hline $18-25$ & $1008(84.0)$ \\
\hline $26-35$ & $183(15.3)$ \\
\hline $36-45$ & $9(0.8)$ \\
\hline \multicolumn{2}{|c|}{ Studentship status as of past 12-months } \\
\hline Not a student & $375(31.3)$ \\
\hline Part-time & $90(7.5)$ \\
\hline Full-time & $735(61.3)$ \\
\hline \multicolumn{2}{|c|}{ Paid job status as of past 12-months } \\
\hline None & $724(60.3)$ \\
\hline Part-time & $303(25.3)$ \\
\hline Full-time & $173(14.4)$ \\
\hline \multicolumn{2}{|c|}{ Unpaid job status as of past 12-months } \\
\hline None & $831(69.3)$ \\
\hline Part-time & $231(19.3)$ \\
\hline Full-time & $138(11.5)$ \\
\hline
\end{tabular}

Overall one-year prevalence of drug use is $14.3 \%$ ( $n=$ 171). The prevalence was higher in males students $17.3 \%(\mathrm{n}=$ 127) compared to their female counterparts $9.4 \%(\mathrm{n}=44))$ with significant difference $(\mathrm{P}<0.01)$. Similarly, there was the highest drug use prevalence among those aged 36 45 years (33.3\%), part-time students in the past 12 months (23.3\%), that had part-time paid job in the past 12 months (23.1\%), and part-time unpaid job (23.8\%) with significant differences $(\mathrm{P}<0.05)$ as shown in Table 2. 


\begin{tabular}{|c|c|c|c|c|c|}
\hline \multirow{2}{*}{ Variable } & \multirow{2}{*}{ Numbers } & \multicolumn{2}{|c|}{ Drug Use } & \multirow{2}{*}{$\chi^{2}$} & \multirow{2}{*}{ P-Value } \\
\hline & & No & Yes & & \\
\hline Institution & & & & 110.855 & $<0.01$ \\
\hline PY & 300 & $238(79.3)$ & $62(20.7)$ & & \\
\hline $\mathrm{CA}$ & 200 & $169(84.5)$ & $31(15.5)$ & & \\
\hline $\mathrm{CE}$ & 200 & $137(68.5)$ & $63(31.5)$ & & \\
\hline UV & 500 & $485(97.0)$ & $15(3.0)$ & & \\
\hline Total & 1200 & $1029(85.8)$ & $171(14.2)$ & & \\
\hline Sex & & & & 14.413 & $<0.01$ \\
\hline Female & 466 & $422(90.6)$ & $44(9.4)$ & & \\
\hline Male & 734 & $607(82.7)$ & $127(17.3)$ & & \\
\hline Total & 1200 & $1029(85.8)$ & $171(14.2)$ & & \\
\hline Age group, y & & & & 9.908 & $0.01 f$ \\
\hline $16-25$ & 1008 & $877(87.0)$ & $131(13.0)$ & & \\
\hline $26-35$ & 183 & $146(79.8)$ & $37(20.2)$ & & \\
\hline $36-45$ & 9 & $6(66.7)$ & $3(33.3)$ & & \\
\hline Total & 1200 & $1029(85.8)$ & $171(14.2)$ & & \\
\hline Student in the past 12-month & & & & 8.038 & 0.02 \\
\hline No & 375 & $331(88.3)$ & $44(11.7)$ & & \\
\hline Part-time & 90 & $69(76.7)$ & $21(23.3)$ & & \\
\hline Full-time & 735 & $629(85.6)$ & $106(14.4)$ & & \\
\hline Total & 1200 & $1029(85.8)$ & $171(14.2)$ & & \\
\hline $\begin{array}{l}\text { Paid Job in the past } \\
\text { 12-month }\end{array}$ & & & & 31.308 & $<0.01$ \\
\hline No & 724 & $652(90.1)$ & $72(9.9)$ & & \\
\hline Part-time & 303 & $233(76.9)$ & $70(23.1)$ & & \\
\hline Full-time & 173 & $144(83.2)$ & $29(16.8)$ & & \\
\hline Total & 1200 & $1029(85.8)$ & $171(14.2)$ & & \\
\hline $\begin{array}{l}\text { Unpaid job in the past } \\
\text { 12-month }\end{array}$ & & & & 23.471 & $<0.01$ \\
\hline No & 831 & $737(88.7)$ & $94(11.3)$ & & \\
\hline Part-time & 231 & $176(76.2)$ & $55(23.8)$ & & \\
\hline Full-time & 138 & $116(84.1)$ & $22(15.9)$ & & \\
\hline Total & 1200 & $1029(85.80)$ & $171(14.2)$ & & \\
\hline
\end{tabular}

Abbreviations: CA, College of Agriculture; CE, College of Education; f, Fisher's Exact test; PY, polytechnic; UV, university.

Past one-year prevalence of various drug use shows that tobacco (9.6\%) and alcohol (8.1\%) had the highest prevalence among the study population. Among the illicit drugs, cannabis was the most used (6.3\%), followed by cocaine $(5.8 \%)$. The detailed account of drug use among the respondents is shown in Table 3.

The analysis of socio-demographic factors associated with drug use in the past 12-month reveals university stu- dents (1.88 times more likely to use drugs compared to polytechnic students), being a male ( 1.55 times more likely to use drugs compared to female), age between 26 - 35 years (1.48 times more likely to use drugs compared to those aged 18 - 25 years), being a part-time student, and having a part-time paid job in the past 12 months (2.16 and 2.11 times more likely to use drugs compared to those that had no part-time studentship status and part-time paid job in the 


\begin{tabular}{|c|c|c|c|c|}
\hline \multirow{2}{*}{ Drug } & \multicolumn{2}{|c|}{ Uses, No. (\%) } & \multirow{2}{*}{$\chi^{2}$} & \multirow{2}{*}{ P-Value } \\
\hline & No & Yes & & \\
\hline Tobacco & $1085(90.4)$ & $115(9.6)$ & 1034.2 & $<0.01$ \\
\hline Alcohol & $1103(91.9)$ & $97(8.1)$ & 1030.5 & $<0.01$ \\
\hline Cannabis & $1124(93.7)$ & $76(6.3)$ & 1083.0 & $<0.01$ \\
\hline Cocaine & $1131(94.3)$ & $69(5.8)$ & 1094.4 & $<0.01$ \\
\hline Amphetamines & $1147(95.6)$ & $53(4.4)$ & 1121.3 & $<0.01$ \\
\hline Hallucinogens & $1149(95.8)$ & $51(4.3)$ & 1129.1 & $<0.01$ \\
\hline Sniffed/inhaled things & $1182(98.5)$ & $18(1.5)$ & 1152.5 & $<0.01$ \\
\hline Tranquillizers & $1159(96.6)$ & $41(3.4)$ & 1152.5 & $<0.01$ \\
\hline Sedatives & $1161(96.8)$ & $39(3.3)$ & 1098.3 & $<0.01$ \\
\hline Opium & $1163(96.9)$ & $37(3.1)$ & 1133.0 & $<0.01$ \\
\hline Heroin & $1180(98.3)$ & $20(1.7)$ & 1152.5 & $<0.01$ \\
\hline Other Opiates & $1160(96.7)$ & $40(3.3)$ & 1117.5 & $<0.01$ \\
\hline
\end{tabular}

past 12 months, respectively) the significant determinants of drug (Table 4 ).

\section{Discussion}

Drug use among students is a public health problem and its academic consequences cannot be overemphasized. However, the current study revealed a considerable drug use among the study population. The past one-year prevalence of $14.3 \%$ was found. This finding is comparable with the result of the recent national population-based drug use survey done in the country that reported a past one-year prevalence of $14.4 \%$ (6). Additionally, this study further reported a prevalence of $13.6 \%$ in the north-east zone of the country which is the setting for the present study (6). Although this national survey did not survey for alcohol and tobacco use. In contrast, the past one-year prevalence of drug use among university students in the southwestern part of the country was higher (22.6\%) than our result (13). Differences in religious and socio-cultural characteristics of the people, and the different numbers of drugs included could be responsible for the observed differences. Similarly, our study revealed the highest drug use among students aged 26-45 years. This finding is in agreement with the findings of other previous studies irrespective of populations covered $(6,14,15)$.

Analysis of individual drugs in our study showed that tobacco had the highest one-year prevalence rate. This result is in agreement with that of a Sudanese study (16). Due to dangers associated with tobacco use, such as chronic obstructive pulmonary disease, cancer of the lung, and coronary heart diseases which could lead to untimely death (17,
18), there is a need for health promotion and protection interventions for the students to cut down on tobacco use and safeguard their health. In contrast, cola nut, stimulants other than the amphetamine-types, and alcohol were respectively reported as the highest drugs used among students of tertiary institutions in South Western Nigeria (10), while national drug use general population-based survey in Nigeria reported cannabis (6). Non-inclusion of tobacco and alcohol among the drugs surveyed may be responsible for this result. Furthermore, our study revealed alcohol as the second most common drug used by students consistent with the result of a previous Nigerian study (10). In contrast, it ranked first in an Ethiopian study (19), and third in a Sudanese study (16). It is noteworthy that alcohol ranked second among the drugs assessed in our study despite alcohol being prohibited in the Muslim-dominated area on religious grounds. Nevertheless, the prevalence rate of alcohol use of $8.1 \%$ recorded by our study is comparable with 5.6\% found among Sudanese university students (16). Similar to our result, an earlier study among secondary school students in Nigeria revealed a similar trend (20). Therefore, effective measures are required to tackle the menace of the use of these two drugs in Nigerian schools in order to enhance academic performance.

Among the illicit drugs, cannabis had the highest past 12-month prevalence congruent with the finding of a previous university and population based-studies, respectively $(10,16,21)$. Cannabis has continued to feature in Nigeria and some other countries as the most commonly used illicit drug (22). When one uses illicit drugs, it has the capacity to interfere with the normal traffic patterns that the neurotransmitters use. This interference can affect the way 


\begin{tabular}{|c|c|c|}
\hline Independent Variable & $\operatorname{AOR}(95 \% \mathrm{CI})$ & P-Value \\
\hline \multicolumn{3}{|l|}{ Institution } \\
\hline PY & 1 & \\
\hline $\mathrm{CA}$ & $0.75(0.46-1.22)$ & 0.24 \\
\hline $\mathrm{CE}$ & $0.13(0.07-0.24)$ & $<0.01^{\mathrm{a}}$ \\
\hline UV & $1.88(1.23-2.89)$ & $<0.01^{\mathrm{a}}$ \\
\hline \multicolumn{3}{|l|}{ Sex } \\
\hline Female & 1 & \\
\hline Male & $1.55(1.04-2.31)$ & $0.03^{\mathrm{a}}$ \\
\hline \multicolumn{3}{|l|}{ Age $(y)$} \\
\hline $18-25$ & 1 & \\
\hline $26-35$ & $1.48(0.95-2.31)$ & $0.08^{\mathrm{a}}$ \\
\hline $36-45$ & $2.61(0.55-12.46)$ & 0.23 \\
\hline \multicolumn{3}{|c|}{ Student in the past 12-month } \\
\hline No & 1 & \\
\hline Part-time & $2.16(1.11-4.21)$ & $0.02^{\mathrm{a}}$ \\
\hline Full-time & $1.25(0.83-1.90)$ & 0.29 \\
\hline \multicolumn{3}{|c|}{ Paid Job in the past 12-month } \\
\hline No & 1 & \\
\hline Part-time & $2.11(1.36-3.27)$ & $0.01^{\mathrm{a}}$ \\
\hline Full-time & $1.50(0.86-2.63)$ & 0.15 \\
\hline \multicolumn{3}{|c|}{ Unpaid job in the past 12-month } \\
\hline No & 1 & \\
\hline Part-time & $1.26(0.80-1.98)$ & 0.32 \\
\hline Full-time & $1.02(0.57-1.85)$ & 0.94 \\
\hline
\end{tabular}

Abbreviations: AOR, adjusted odds ratio; $\mathrm{CA}$, College of Agriculture; CE, College of education; PY, polytechnic; UV, university.

${ }^{\mathrm{a}}$ Significant at $\mathrm{P}<0.05$

the brain processes and retains information, thereby influencing how such an individual thinks, learns, remembers, focuses, and concentrates. Therefore, students who use illicit drugs usually experience poor academic performance (lower grades, a higher rate of absenteeism from school, and an increased likelihood of dropping out of school) (23). This highlights the need for effective drug preventive policy in schools. It is worthy to note that schools can make a difference through their programmes and learning opportunities, and the support that they offer to their students (24). This policy is critical because it will serve as guidance to the school managers, teachers, and staff, as well as families, community agencies, and other stakeholders, in making drug education practice-related decisions within school communities in order to reduce drugrelated harm to students. However, the relatively high use of cannabis among Nigeria students may be connected to their easy availability and low cost. Therefore, the regulatory agency saddled with the responsibility of control of illicit drugs/substances in Nigeria should step up the war against its cultivation, sales, and trafficking in a bid to make them unavailable for the students to access. Additionally, this war inadvertently can reduce supply and increase its costs and adulteration which in turn will constitute a barrier to access and in the long run reduces use.

The analysis of the socio-demographic determinants of drug use after adjusting for confounders showed that university students were significantly more likely to use drugs than polytechnic students. Policies vary among institutions, and institutions that are more liberal with drugs use are likely to have more students using drugs for nonmedical purposes. Although further qualitative studies are needed to clearly explain this finding. In our study, part-time students in the past 12 months were significantly more likely to use drugs than those who were not students at all during the past 12 months. Access to fund could be responsible for this finding because a sizeable proportion of these part-time students had paid part-time jobs in the past 12 months. Male students were more likely to use drugs compare to their female counterparts. This result is consistent with the findings of previous Nigerian and Sudanese drug use studies which reported the same sexbased differences in drug use $(6,13,16,21)$. These findings may be due to male trait and show of power often exhibited by male students which may encourage drug use. Additionally, the use of alcohol is frowned at on a religious ground in our study setting which a Muslim dominated area, but such society tolerates smoking tobacco in various forms as part of the social lives of males. Furthermore, students within the age range of 26 to 35 years were more likely to use drugs than their younger peers. This result is consistent with that of a previous national survey of drug use in Nigeria that reported that drug use was most prevalent among those within the age range of 25 and 39 years (6). This finding demonstrates that middle-aged students are more vulnerable to the menace of drug use. Hence, the need for preventive interventions targeted at this age group in order to avert the consequences of drug use in the higher education institutions. Finally, students that had part-time paid jobs in the previous 12 months were also significantly more likely to use drugs compared to their counterparts who had none or full-time paid jobs in the past 12 months. This finding suggests that stipends earned from part-time jobs may translate to greater purchasing power of drugs for this category of students.

The main limitation of the study is the quantitative and cross-sectional design which could not satisfactorily identify and explain all the significant determinants of drug 
use. A qualitative longitudinal study in which students are allowed to talk freely and followed up will be most appropriate for evaluation of the changing trend of drug use over time. Secondly, under-reporting was a threat in the study due to the sensitive nature of drug use (society frowns at their use and the Nigerian law also prohibits their non-medical use), so participants may not have been honest while completing the questionnaire. Lastly, inability to obtain data on students' enrollment from the management of the study schools made recruitment of participants through stratification to ensure representation impossible.

\subsection{Conclusions}

Our study reveals that a considerable proportion of students of higher institutions of learning in Nigeria use drugs. Drug use has grave implications for high school students and may result in mental health disorders and poor academic performance. This highlights the importance of an effective drug prevention policy in higher institutions of learning. Our study identified being a university, male, and part-time student, and having a paid part-time job in the past 12 months as the significant determinants of drug use. Therefore, interventions targeted at these identified factors should be provided to effectively prevent the effects of drug use on these categories of students and improve mental wellbeing, and enhance learning and academic performance. The interventions that include combinations of interactive teaching and learning, building highly specific resilience skills, provision of educational information, and students' direct involvement in the delivery of such programmes are recommended.

\section{Footnotes}

Authors' Contribution: Study concept and design: RNO. Acquisition of data: UL. Analysis and interpretation of data: RNO. Drafting of the manuscript: RNO. Critical revision of the manuscript for important intellectual content: RNO. Statistical analysis: RNO. Administrative, technical, and material support: UL. Study supervision: RNO.

Conflict of Interests: The authors declared no conflict of interest.

Ethical Approval: The study protocol was approved by the Faculty of Pharmacy Research Review Board, University of Maiduguri prior to data collection.

Funding/Support: This study did not receive any funding or support.

\section{References}

1. United Nations Office on Drugs and Crime (UNODC). World Report 2019. 2020, [cited Sep 20, 2020]. Available from: http://www.unodc org/wdr.

2. United Nations Organizations on Drug Council (UNODC). World Health Organization expert committee on dependence producing drugs. Fourteenth report urban adolescents, child development. $2005.14 \mathrm{p}$.

3. World Health Organization (WHO). Substance abuse refers to the harmful or hazardous use of psychoactive substances, including alcohol and illicit drugs. 2019, [cited Sep 20, 2020]. Available from: http://www.who. int/topics/substance_abuse/en.

4. National Drug Law Enforcement Agency (NDLEA), Drug data collection and research, Lagos: Drug Demand Reduction Unit, National Drug Law Enforcement Agency. 1997.

5. Lipari RN, Jean-Francois B. A day in the life of college students aged 18 to 22: substance use facts. 2016, [cited Sep 20, 2020]. Available from: https://www.samhsa.gov/data/default/files/report-2361/ ShortReport-2361.html.

6. United Nations Office on Drugs and Crime (UNODC). Drug use in Nigeria. 2018.

7. Haladu AA. Outreach strategies for curbing drug abuse among outof-school youth in Nigeria: A challenge for community based organization (CBOS). In: Garba A, editor. Youth and drug abuse in Nigeria: Strategies for counselling, management and control. Kano: Matosa Press; 2003.

8. World Health Organization Report (WHO). Management of substance abuse: Alcohol. Geneva; 2009, [cited Sep 20, 2020]. Available from: http://www.who.org.

9. Essien CF. Drug use and abuse among students in tertiary institutions-the case of federal university of technology, Minna. J Res National Develop. 2010;8(1):35-42.

10. Onifade PO, Somoye EB, Ogunwobi OO, Fadipe B, Fela-Thomas AL, Adeniji MA. Drug use, consequences and perceived accessibility in three Nigerian universities. Open J Psychiatry. 2014;4(1):60-7. doi: 10.4236/ojpsych.2014.41009.

11. Johnson OE, Akpanekpo EI, Okonna EM, Adeboye SE, Udoh AJ. The prevalence and factors affecting psychoactive substance use among undergraduate students in University of Uyo, Nigeria.J Commun MedPrimary Health Care. 2017;29(2):11-22.

12. World Health Organization (WHO). A methodology for students' drug use survey. Geneva: WHO Offset Publication;1980. 50 p.

13. Umukoro OL, Taiwo A, Maroh I, Mofoluwake M. Prevalence and Patterns of Drug Abuse among Students of Tertiary Institutions in Abeokuta, Ogun State, Nigeria. Int J Psychiatry. 2016;1(1). doi: 10.33140/ijp/01/01/00003.

14. Babalola E, Akinhanmi A, Ogunwale A. Who guards the guards: drug use pattern among medical students in a nigerian university. Ann Med Health Sci Res. 2014;4(3):397-403. doi: 10.4103/2141-9248.133467. [PubMed: 24971216]. [PubMed Central: PMC4071741].

15. van Wel JH, Rosiers JF, Van Hal G. Changes in Drug Use Among Belgian Higher Education Students: A Comparison Between 2005, 2009, and 2013. Subst Use Misuse. 2016;51(9):1232-8. doi: 10.3109/10826084.2016.1162811. [PubMed: 27219643]

16. Osman T, Victor C, Abdulmoneim A, Mohammed H, Abdalla F, Ahmed A, et al. Epidemiology of Substance Use among University Students in Sudan. J Addict. 2016;2016:2476164. doi: 10.1155/2016/2476164. [PubMed: 27006856]. [PubMed Central: PMC4783543].

17. Das SK. Harmful health effects of cigarette smoking. Mol Cell Biochem. 2003;253(1-2):159-65. doi: 10.1023/a:1026024829294. [PubMed: 14619966]

18. Jha P. The hazards of smoking and the benefits of cessation: a critical summation of the epidemiological evidence in high-income countries. Elife. 2020;9. doi: 10.7554/eLife.49979. [PubMed: 32207405]. [PubMed Central: PMC7093109]. 
19. Ayalew M, Tafere M, Asmare Y. Prevalence, Trends, and Consequences of Substance Use Among University Students: Implication for Intervention. Int Q Community Health Educ. 2018;38(3):169-73. doi: 10.1177/0272684X17749570. [PubMed: 29310534].

20. Manyike PC, Chinawa JM, Chinawa AT, Obu HA, Nwokocha ARC, Odetunde OI. Correlates for psycho-active substance use among boarding secondary school adolescents in Enugu, South East, Nigeria. BMC Pediatr. 2016;16:78. doi: 10.1186/s12887-016-0615-9. [PubMed: 27282877] [PubMed Central: PMC4899923].
21. Adamson TA. Descriptive national survey of substance use in Nigeria. JAddict Res Ther. 2015;6(3). doi: 10.4172/2155-6105.1000234.

22. United Nations Organizations on Drug Council (UNODC). World Drug Report 2010 United Nations Publication, Sales No. E.10.XI.13. New York: United Nations Office on drugs and crime; 2010.

23. Substance Use Among 12th Grade Aged Youths by Dropout Status, The NSDUH Report, Substance Abuse and Mental Health Administration. 2013.

24. Australian Government (Department of Education. Principles for school drug education. 2004. $61 \mathrm{p}$. 